This is a self-archived version of an original article. This version may differ from the original in pagination and typographic details.

Author(s): Venäläinen, Satu; Virkki, Tuija

Title: Struggles for moral value and the reproduction of gendered and racialised hierarchies in online discussions of violence

Year: 2019

Version: Published version

Copyright: @ 2019 SAGE publications

Rights: In Copyright

Rights url: http://rightsstatements.org/page/InC/1.0/?language=en

Please cite the original version:

Venäläinen, S., \& Virkki, T. (2019). Struggles for moral value and the reproduction of gendered and racialised hierarchies in online discussions of violence. Sociological Review, 67(6), 1367-

1382. https://doi.org/10.1177/0038026119866635 


\title{
Struggles for moral value and the reproduction of gendered and racialised hierarchies in online discussions of violence
}

Satu Venäläinen Faculty of Social Sciences, University of Helsinki, Finland

Tuija Virkki Faculty of Humanities and Social Sciences, University of Jyväskylä, Finland

\begin{abstract}
The article examines online discussions in Finland that focus on violence committed by Finnish women, on one hand, and non-white migrant men, on the other. Drawing on the perspective of sociology of value, the article illustrates how these discussions function as sites of struggles over moral worth in a contemporary context characterised by crises of both male and white hegemony. The authors suggest that, through the discussions, these current crises are projected on migrant men and certain groups of women, who thereby become construed as morally reprehensible. The analysis sheds light on processes of (re-)legitimating the moral virtue historically attached to both masculinity and whiteness, and thereby shows how gendered and racialised hierarchies are reproduced in the context of meaning-making around the issue of violence. Also discussed is how these dynamics and the process of reproduction via discourse draw upon historically recurring meanings and evaluations while simultaneously tailored to contemporary circumstances. The tailoring is performed via explicit reference to the value of gender equality, which serves a dual function: re-inscribing moral value in white masculinity while excluding from the circuits of value both racialised masculinities and Finnish women portrayed as doing gender and whiteness in the 'wrong' way. These processes give the discussants room for justifying hate and violent exclusion of such women and migrant men while also muting any dissenting voices attempting to resist circulation of the derogatory meanings.
\end{abstract}


Keywords: gendered violence, migrants, moral evaluations, sociology of value, women

\section{Introduction}

The topic of violence is morally charged, and therefore it easily becomes a vehicle for moral evaluation and the associated construction of moral hierarchies and distinctions between differently positioned groups of people (Baird, 2009). Debates about violence, particularly in online contexts, tend to entail polarised argumentation and taking of a moral stance (eg BouFranch \& Garcés-Conejos Blitvich, 2014; Dragiewicz \& Burgess, 2016). There has been heated debate about whose violence should be the primary focus of public discussion and which groups of people are the principal perpetrators of violence. The significance of gender has been at the core of much of the debate: views expressed by feminist actors on links between masculinity, power, and violence have often been fiercely opposed by those who claim instead that, with our societies no longer being male-dominated, women's violence is actually a more pressing social problem than violence against women today (Dragiewicz \& Burgess, 2016). Similar dynamics have appeared in discussions, online and offline, that focus on the threat of gendered violence purportedly caused by increased immigration: in attempts to identify those groups of men who are most likely to perpetrate violence against women, non-white migrant men, especially Muslim immigrants, are recurrently cast as the top suspects (Brubaker, 2017; Törnberg \& Törnberg, 2016). These portrayals have been recurrently appealed to in both online and offline efforts to garner support for populist and antiimmigration views and practices.

In this paper, we analyse the reproduction of moral hierarchies and distinctions in online discussions centred on violence perpetrated by women and on that committed by non-white migrant men. The rationale for examining these discussions side by side stems from an 
observation that common threads run through them, specifically in terms of meaning-making wherein public morality is negotiated. Proceeding from such observations, we propose that both sets of discussions act as central sites for attempts to (re-)establish gendered and racialised hegemony through processes of moral subject formation (Skeggs, 2005) in the face of recent societal changes in Finland and elsewhere in the Western world. In particular, these attempts respond in many ways to feminist critiques of men's violence against women that have posed challenges to white male hegemony (cf. Dragiewicz \& Burgess, 2016). These challenges constitute one part of what has been labelled as a crisis of male hegemony (eg Ging, 2017; see also Dragiewicz, 2011) that is at the core of the global phenomenon of 'angry white men' (Kimmel, 2013) or 'frustrated masculinities' (Keskinen, 2013). In essence, this crisis is rooted in notions that men as a previously powerful group have lost their privileges in consequence of gender-equality efforts having gone too far and women having grown too powerful. These ideas have gained further popularity amid recent societal changes connected with increased immigration to many European countries. Focusing on society's reactions to the rise in immigration in the Finnish context, Suvi Keskinen (2018) has developed the concept of a crisis of white hegemony. In echoes of the crisis of male hegemony, the sense of crisis here is based on perceptions that the white Finnish nation is under threat from an uncontrolled influx of immigrants and from multiculturalism that many claim has gone too far (Keskinen, 2013).

These parallel crises are manifested in ways that are specific to the cultural context. In the Finnish context, they clash with widely accepted notions of Finland as a forerunner in terms of equality - the idea of equality among individuals is regarded as a cornerstone of Nordic welfare states, Finland among them. Hence, the discourses of these crises adapt to this idealisation of equality, while also shaping it somewhat themselves. One relevant factor in this regard is that despite the idealization of equality, shortcomings have been noted to exist in Nordic practices related both to gender equality and to the respect for cultural diversity 
(Magnusson, Rönnblom, \& Silius, 2008). In Finland, the shortcomings manifest themselves in phenomena such as high rates of men's violence against women and hate speech directed at women and non-white migrants alike (European Union Agency for Fundamental Rights, 2014; Pöyhtäri, Haara, \& Raittila, 2013). Although our examination focuses on the specific case of Finland, it is noteworthy that its relevance extends beyond any single country. On account of the global nature of online interaction, the Finnish discussions are part of globally circulating discourses and, as such, echo broader patterns within efforts to (re-)establish gendered and racialised hierarchies.

We are not alone in highlighting the similarities and co-occurrence of crises related to, on one hand, gender relations and equality and, on the other, ethnicity, race, and immigration. Several scholars before us have drawn attention to the similarities, often looking especially at the increase in online hate speech against women (particularly feminists) and migrants, along with the intersections of gender, ethnicity, and race in the context of these forms of online expression of hate (eg Keskinen, 2013, 2018; Saresma, 2018; Sundén \& Paasonen, 2018). However, the literature has not focused specifically on the moral evaluations that unite these relatively new discourses and the associated social dynamics. We argue that such a focus affords a nuanced understanding of processes whereby both women and migrant men can be constructed as morally legitimate objects of hate and denigration in ways that enable reestablishment of the gendered and racialised hierarchies threatened by recent social changes. To do this, we employ the perspective of sociology of value, the key principles of which are outlined below.

\section{Theoretical considerations: Sociology of value}


To address the moral dimensions of online discussions of gendered violence, we draw on theoretical insights provided by what is known as sociology of value. The scholarly work of Beverley Skeggs $(1997,2005)$ provides useful theoretical tools for analysing the role of moral evaluations in the reproduction of gendered and racialised power. Her work is based on Pierre Bourdieu's (1989) ideas about the interrelations among various forms of capital economic, social, and cultural, for instance - and subjects' social positions. The key aspect of the reproduction of social hierarchies is the uneven distribution of capacity to transform these forms into symbolic capital. This conversion takes place through symbolic struggles over value wherein certain forms of capital are perceived as legitimate and get recognised accordingly. The overall value ascribed to subjects shifts in line with their ability to both accrue these and convert them (Skeggs \& Loveday, 2012).

Skeggs has extended Bourdieu's understanding of symbolic capital through feminist and critical race theory, which has allowed for an intersectional view of how value is distributed among subjects and differentially attached to them within the contemporary social and symbolic circuits of value that create classed, gendered, and racialised hierarchies (Tyler, 2015). Her crucial contribution from the standpoint of our work is the emphasis on the moral aspects of valuing and the ways in which the systems of moral evaluation, new and old, sprout from relations of power between social groups. These power relations, in turn, emerge and are sustained through differentially assigning moral value to specific social groups (Skeggs, 2005). For instance, masculinity and whiteness are strongly associated with symbolic capital in general, while the ability to capitalise on femininity and non-whiteness is relatively restricted. Gender and race, along with other systematic social differences, are hence seen as providing central relations in the context of which capital comes to be organised and valued (Skeggs, 1997). What is key in classification-linked value struggles along gender, class, race, and various other lines is the level of access to a position of authority 
from which one can issue and enforce moral value judgements, thereby assigning moral value (Skeggs, 2005). Our analysis illuminates dynamics through which both moral value is attached to social groups and authority to make moral judgements is claimed at the level of symbolic representation focusing on violence, instead of attending to the full complexity of value accrual at the level of lived experience.

Hence sociology of value offers a larger theoretical framework, within which we situate the conceptualisations of hegemonic masculinity (Connell, 2016) and hegemonic whiteness (Hughey, 2010) so as to grasp more fully the intersecting ways in which excluding some groups of women and migrant men from circuits of value is legitimated by the dominant symbolic structure. Hegemonic masculinity is considered here as a set of norms that operates in people's inclusion in and exclusion from the realm of moral value by dint of their gender and other, intersecting systems of social distinction. These norms are attached to attributes such as dominance, power, superior rationality, and self-control, and they serve to perpetuate inequalities both between men and women and among (variously positioned) men. In our analysis below, we suggest that references to these qualities function as a central mechanism whereby the online discourse about violence (re)attaches value to white masculinity while eroding the moral worth of femininities and non-hegemonic masculinities.

While highly useful, the concept of hegemonic masculinity does not allow grasping in depth the ways in which whiteness may in some contexts allow capitalising on femininity and thus producing hierarchies among femininities too. The notion of hegemonic whiteness helps to fill this gap. It is centred on the value distinctions between 'whites' and 'non-whites' while allowing for tapping in to systems of evaluation that enact intra-racial distinctions also, in the context of which certain ways of 'being white' may mark subjects as of lesser worth. By 
utilising these two concepts in combination, we are able to offer a more in-depth analysis of the intersections between gender and race in the relevant online discussion.

\section{Data and methods}

The Internet and social media have become ever more central fora for morality negotiation related to current social phenomena (Pantti, 2016). This makes online discussion fora fruitful sources of data that tap into processes of moral evaluation also in the context of dialogue focusing on violence. We analysed two separate datasets, both of which were collected in 2017 in connection with a larger project examining discourses of violence in the contemporary Finnish context. Both datasets are composed of discussion threads from Finnish online discussion fora and blogs that were found by means of Web searches conducted with Google and site-specific text-search tools.

Dataset 1 consists of threads of conversation that focus on violence committed by women. The 98 discussion threads, containing 3,190 comments, were found with the search terms 'violence + women', 'women's violence', and 'intimate partner violence experienced by men'. The data, from 2007-2016, were obtained from six discussion fora (Finland's most popular general-interest online discussion forum and the forums of a national newspaper, a regional newspaper from northern Finland, a teenage girls' magazine, a baby-focused magazine, and a science magazine) and nine comment areas on blog sites. One of the writers of the blogs whose comment areas were analysed has become well-known as an advocate of the men's rights movement in Finland, while the others do not have a similar profile; they comment on a wide range of societal issues. The discussion threads were triggered by various writings, by reporters or members of the public, commenting either on the relations between women and violence in general, particularly intimate-partner violence by women, or on recent findings 
from research into intimate-partner violence, such as a 2010 study that focused specifically on men's victimisation (Heiskanen \& Ruuskanen, 2010).

Dataset 2 is a set of online discussion threads about violence committed by migrant men in Finland. The data cover the years 2015-2017. This material was obtained from five discussion fora (one general forum and the discussion boards of a national and a regional newspaper, a magazine for teenaged girls, and a family magazine) and eight comment areas of blog sites. The 463 discussion threads, with 21,789 comments, constituting this dataset were found with the search terms 'violence + migrants' and 'violent migrants'. The discussion was prompted by reporting (in the case of online newspapers' comment sections) or comments from other citizens (in cases of material on blog sites or in non-newspaper-based discussion fora) about instances of violent crime committed by migrant men. Among these are various cases of sexual violence and rape in which migrant men were suspects during the so-called refugee crisis of 2015 and an allegedly terrorist knife attack on women by an asylum-seeker in 2017. Although the discussions centred largely on non-white male asylum-seekers or refugees from the Middle East and Africa, the discussants often employed the general term 'migrants'.

Both datasets were collected with the purpose of accumulating a wide range of conversation among the general population that is focused on the above-mentioned themes. For this reason, we sought data from several types of discussion forum rather than confine our attention to, for instance, sites known for their anti-immigration or anti-feminist leanings. For example, three discussion fora in our data belong to magazines published primarily for a female readership. Naturally, the anonymous nature of online communication means that we cannot know who the discussants on these sites are, what kinds of political views they espouse, or much else about their social positions. Following widely accepted ethics guidelines for Internet research (eg Markham \& Buchanan, 2012), we have attempted to 
safeguard the posters' anonymity ourselves by such means as not identifying the forum where the post extracted from in the analysis below was made (we reference the posts analysed only by the posting date), and the excerpts are given in translation from Finnish into English, which renders it difficult to trace them and hence potentially identify the originator. Furthermore, all discussion threads found by the searches were publicly accessible at the time of data-collection, and can thus be considered as within the public realm. While we acknowledge that ethics questions do remain, pertaining to the potential questionability of highlighting views that, as the analysis section illustrates, largely reiterate misogynist and racist meaning-making, we contend that the value of knowledge gained through dissecting processes in the forming of such views, which can be utilised for intervening in those processes, outweighs such concerns.

We began by analysing each dataset separately, following the principles of discourse analysis (eg Taylor, 2001). The analyses involved several iterations of reading the data, coding the material for recurrent themes and claims, identifying patterns in ways in which meanings were attached to violence and its perpetrators, and considering how those patterns tie in with broader discourses. The discursive orientation of the analysis entailed attending to not just the contents of the online discussions but also how language was used in the processes of constructing meanings, alongside the functions of meaning-making in the discussions. Accordingly, we have approached meaning-making on Internet platforms as social action aimed at accomplishing something, such as justifying certain actions or one's social positioning, performing an identity, or establishing relational hierarchies.

The second stage of analysis involved setting the recurring meanings identified in stage 1 in the datasets in dialogue with each other, which helped us see the links between the datasets in a new way. The themes focused on in this paper - moral evaluations, struggles over value, 
and reproduction of gendered and racialised hierarchies - emerged in this stage of the analysis. This dialogical examination hence facilitated deepening the analysis and thereby yielded a more comprehensive understanding of the online conversations' dominant meaning-making processes and dynamics. We consider these processes next, outlining the main areas of similarity between the datasets while also describing their specific, distinguishing features.

\section{Locating the problem of violence}

The main similarity in discursive dynamics between the two datasets arises through recurring claims that white Finnish men are falsely accused of violence against women and thus unfairly criticised, devalued, and even demonised in contemporary discussions of violence. These claims are often accompanied and emphasised by expressions of indignation and anger aroused by what is depicted as gross injustice. Several writers present claims about Finnish men being falsely labelled as violent by making references to the prevalence of 'false propaganda about Finnish men's violence and evilness' (22 December 2010), 'constant blasting of Finnish men' (12 January 2010), or 'feminist sh*t aimed once again at labelling us men as evil bastards' (23 November 2009).

All of this is claimed to have led to a situation in which 'white Finnish heterosexual men are the most undervalued group of people' (21 August 2017), a group that 'is considered to be the lowest of filth from the point of view of Finnish women' (28 August 2017). The devaluation referred to is often depicted as a relatively recent phenomenon, as with this claim: 'Women's valuation of, and respect for, men has clearly declined radically in the last few decades' (4 January 2010). It is this very notion of white Finnish men's widespread, baseless demonisation and their associated devaluation that gives impetus to efforts to re-inscribe moral value in white masculinity in the online discussions. Our analysis indicates that this is 
done in two main ways: firstly, by constructing violence committed by women and non-white migrant men as a more significant problem than violence by white Finnish men (problematising) and, secondly, by constructing violence committed by women and by nonwhite migrant men as an indication of the overall moral inferiority of these groups (inferiorising).

Central to the problematisation of women's and non-white men's violence is the value attached to non-violence. As the problem of violence is primarily pinned to women and non-white migrant men, it is simultaneously detached from white Finnish men. For instance, in dataset 2, the illegitimacy of the putative devaluation of white Finnish men is constructed by claiming a non-violent identity for them, in stark contrast to the alleged threat of violence posed by migrant men:

Women are scared of terrorism and rape. Both have increased because of migrants, yet there is an overwhelming amount of hate against Finnish men too, and contempt for them. When will the ordinary Finnish man get respect and even admiration? Why do women hate men even though the typical Finnish man wouldn't harm a fly? (21 August 2017)

Portrayals such as this enable connecting relative non-violence to the category Finnish men and, thereby, casting off the image of them as morally questionable actors that is rendered salient by their high rates of violence against women (eg Clarke, 2011). In fact, in many of the discussion threads in both datasets, these numbers were brought up explicitly, and they were often responded to by highlighting the violence of people other than Finnish men:

Could one of you so-called tolerant people explain why you defend the actions of migrant rapists? You often compare them with Finnish men by saying: 'But 
Finnish men rape too!' Even if, by looking at statistics, we can see that the number of rapes committed by migrants is a bigger problem. It is a problem that should be talked about, and something needs to be done to solve it so that we can keep Finland safe for everyone. (13 October 2015)

As do several other comments in the data, the extract above distinguishes between sexual violence perpetrated by Finnish men and that by migrant men, highlighting the severity of the latter while downplaying the significance of the former for Finnish security. Similarly, rather blunt claims about the greater outrage merited by violence from Finnish women in comparison with Finnish men, particularly in intimate relations, appear regularly in dataset 1 . Here, however, the meaning-making patterns are of a slightly different sort, highlighting the severity of women's violence relative to men's by portraying Finnish men as neglected victims of intimate partner violence:

According to current research findings, women commit aggravated domestic violence more than men, and still violence experienced by men is disregarded. Every blow hurts, and not all wounds depend on the size of the bruises or are visible. Equality should be extended also to seeing men as victims, and especially as victims of violence, as just as 'valuable' as women in the eyes of society and the law. (20 November 2016)

Several discussants directly connected this disregard for Finnish men's victimhood caused by women's violence to these men's baseless demonisation linked with being falsely labelled as violent. The connection was made, for instance, by claims that women's violence tends to be overlooked in cases of spousal conflict and that statistics get distorted accordingly, therefore giving undue prominence to violence committed by Finnish men. Hence, the argument is that 
'if in these cases the judicial system and the police were more just in their treatment of men and women, the numbers of violence-against-women cases would get significantly smaller' (24 April 2010). In casting suspicion in this way on statistics showing a high incidence of violence by Finnish men, in a manner reminiscent of the posts on non-white migrant men's violence, attempts are made to portray Finnish men as less violent than what the statistics imply. Some posters even asserted that women who have turned to violence take active part in the creation of the false image of Finnish men's violence by making false claims that they have been abused, so as to benefit - for example, in divorce proceedings: 'There are cases where a violent woman has managed to label a man as violent and on this basis has been granted, among other things, the custody of children after a divorce' (25 March 2012).

Even though these sets of conversations focus on different types of violence overall (intimate-partner violence in the case of women and sexual violence in the case of migrant men) and were triggered to some extent by different societal phenomena, both recurrently construct violence by women or migrant men as a social problem worthy of great concern and condemnation. Furthermore, in both datasets this problematisation is tied in with comparisons to violence committed by Finnish men in ways that afford downplaying its societal significance or, relatedly, for disputing the validity of statistics attesting to its high prevalence.

\section{Inferiorising women and migrant men}

The second way of repudiating claims of white Finnish men's violence and reattaching value to white masculinity is by inferiorising women and non-white migrant men through casting those groups' violence as evidencing qualities that attach lesser moral worth to these groups and to the identities constructed for their members. These portrayals centre on the moral 
value attached to the capacity of exercising responsible self-control (Skeggs, 2005), in which both women and non-white migrant men are often portrayed as lacking, while Finnish men may be depicted simultaneously as possessing it in abundance. Below is an example of how volatility, lack of control, and irrationality are attached to violence committed by women, with the effect of women as a social group being cast as naturally more aggressive and unpredictable than men (in the context of these discussions, the latter category seems to refer specifically to Finnish men):

I have noticed among people close to me that women are much more violent than men. Women very readily attack a man if things don't go the way [the woman thinks] they should, and in those situations the man can't do anything really [...]. Women also get angry more easily than men - because extremely few women don't get pissed off if a man, even in a calm manner, expresses a differing, reasoned opinion (the man is usually right). (26 January 2010)

In the extract above, the irrationality of women's violence is contrasted against what is characterised as men's rational and controlled demeanour. These portrayals rely on historically recurring notions of women's violence as expressive and emotive, and thus as less controlled than men's assumedly more instrumental violence (Campbell \& Muncer, 1994). What is particularly significant here is the way in which attaching self-control to the category of men but not to that of women attests both to men's relative non-violence and to their superiority as rational, controlled human beings.

While the online conversations about female-perpetrated violence typically attach the capacity for self-control to the generic category of men (albeit evoking the image of specifically Finnish white men), thus doing the work of enacting gender differences, similar 
meanings employed in the discussions of violence by non-white migrant men are central to constructing hierarchical distinctions within the category 'men'. Whereas the normativity of masculine self-control and rationality is taken as fundamental to white masculinity, non-white migrant men are frequently portrayed as coming from inherently violent, uncivilised, barbaric, and primitive cultures, and as therefore unable to control their violent and sexual urges:

Why do we accept these intellectually retarded, horrid apes entering our country? It has already been noticed that they think only with their lower body parts. They aren't able to resist their animalistic urges. (24 November 2015)

Such depictions of dangerous foreigners have historical roots in the colonial myth of non-white men as wild animals attacking white women, which has served as justification for imperialist domination of non-Western regions (Nagel, 2003). This myth lies at the heart of a racialised moral hierarchy separating white civilisation and non-white primitiveness. However, the moral superiority of whiteness has historically been conflated with the moral superiority of white masculinity (Baird, 2009). Linked to this is the notion of white men's moral superiority as based not only on their self-control and rationality but also on their position as protectors of white women against the violence of non-white men. The discussants emphasise this position when referring to violence committed by non-white migrant men - even though several claim that it does not gain recognition and respect from Finnish women:

When will Finnish women start to acknowledge Finnish men's genetically driven need to protect Finnish women? I'm sure there will come a time when Finnish women start respecting nice and decent men, but it requires there to first be an influx of hundreds of thousands of representatives of foreign cultures. 
There probably need to be bloody attacks every week before the Finnish woman accepts the thought that the 'Nazi' and the 'racist' she has defamed might in fact want nothing but good things for the Finnish woman and want none of those bad things for Finnish society. (28 August 2017)

The protector position effectively attaches value to the category of white Finnish men, since it affords associating various moral virtues with them: chivalry, responsibility, respectability, decency, etc. (Young, 2003). Furthermore, these descriptions legitimate white Finnish men's position as the natural, righteous defenders of not only Finnish women but also the nation and its borders, for which women are commonly a proxy in the cultural imaginary (eg YuvalDavis, 1997).

What most clearly unites the above-mentioned construction of non-white migrant men and of Finnish women as more violent by nature and as irrational and uncontrollable - at least within the value system that valorises self-control - is that both reproduce moral hierarchies and distinctions by attributing negative moral value to those two groups and, correspondingly, positive moral value to the latter. That said, the historically intertwined processes in the reproduction of racialised and gendered hierarchies are generally reframed in today's discussions by two separate, though not unrelated, notions of gender equality. In order to mesh with contemporary societal contexts, the older, colonialist myths of non-white men's primitive violence against white women are utilised in ways that emphasise respect for gender equality as an essential element of civilisation (see also Brubaker, 2017). The online conversations attest to this in how the representation of non-white migrant men as violent by nature is often linked with a sense that their violence is a cultural trait that is incompatible with the core Finnish value of gender equality: 
The argument that 'Finnish men rape too' doesn't work here. This isn't about any type of isolated incident in which there was a single lapse of judgement under the influence of alcohol. This case of migrant rapists represents a more general statement about Finnish culture and women: these migrant men think that the Finnish woman is a bit too self-sufficient and provocative. These men represent a culture opposite the Finnish one. (12 March 2015)

In the extract, rapes by Finnish men are attributed to momentary errors of judgement. Those committed by migrant men are, in contrast, characterised as determined by a cultural background that is incongruent with Finnish values, on account of its backwardness in terms of gender relations. The contrast works to distinguish what are constructed here as non-violent, equality-endorsing white Finnish men from patriarchal, violent 'outsiders'. This process is coupled with not only constructing difference between migrant men and Finnish women but also the sexualization of the latter. This involves a gaze that constructs them as 'provocative' only from the perspective of migrant men, not Finnish men. Thus, there is an insi that the Finnish men are not troubled by women's (sexual) agency that further consolidates the distinction between Finnish and non-white migrant men.

The notion of equality as a specifically Finnish value is recurrently drawn upon also in the threads about violence committed by women, but usually in somewhat different ways. Here the notion of 'equality having gone too far' (Keskinen, 2013; see also Dragiewicz, 2011) is central in the portrayals of women's violence, where (Finnish) men are presented as occupying a less advantaged position than women do: 
This is what women's equality is like. Women use more violence than men. But women don't even consider it to be violence. Because the man deserved it. On top of this, other women laugh at the man [on the receiving end of it]. (31 May 2013)

The relationship between women and men that is constructed in portrayals such as this is unequal, with women being presented as disrespectful not only toward men but also to the ideal of equality, having purportedly created their own version of it, a contemptuous one. While Finnish equality is depicted in portrayals such as this as being given unfavourable lip service, and is attached to meanings quite different from those appealed to in conversations about non-white migrant men, similarly to the positioning of migrant men in the latter discussions Finnish women are presented here as disrespecting this core value of Finnish culture. What distinguishes the portrayals of Finnish women and migrant men, however, is that the former is in fact centrally based on insinuations that equality is not all good but can also go too far. The analysis below further illustrates this.

\section{Enacting exclusion from circuits of moral value}

We posit, on the basis of our analysis of the two datasets, that the online discussions about violence constitute a highly contested battleground for struggles over moral value, through which hierarchical distinctions are made along gender and race lines (Skeggs, 2005; Skeggs \& Loveday, 2012). As moral value cannot be permanently attached to any particular social group, it is subject to ongoing struggles, re-inscriptions and circulation through historically contingent and evolving discursive processes. As we have illustrated, the value attached to gender equality figures centrally in such struggles in both contexts of discussion. What we find most noteworthy is that in these conversations the very same value that feminists have mobilised in questioning the seemingly self-evident nature of symbolic power of white 
masculinity gets employed repeatedly in ways that reproduce gendered and racialised hierarchies. In other words, we find that the patterns identified in the data represent efforts to capitalise on the core ideal of gender equality for purposes of reclaiming moral virtue for white masculinity. There is great similarity with the political rhetoric of right-wing populists and anti-immigration activists who seek to reimagine whiteness and masculinity by appropriating ideals of gender equality to exclusionary ends (Keskinen, 2013). The term 'femonationalism' coined by Farris (2017) describes how such seemingly oppositional forces, such as right-wing nationalism and certain strains of liberal feminism, share the belief in the supremacy of western values and depict racialised men as dangerous to those values and, most importantly, to the value of gender equality.

In the material we have analysed, however, the value of gender equality is appealed to for excluding from the circuits of value not only racialised masculinities but also those Finnish women who seem to do gender and race in the 'wrong' way. In addition to assertions about many women now being more violent than men, both datasets feature claims that Finnish women have become 'overly dominant alpha women' (15 October 2015), a development that ostensibly has led to 'tyranny of Finnish women who keep starting a row' (19 August 2017). The titles of some threads focused on women's violence - such as 'Has the woman gone from soft to a violent monster?' (11 January 2010) and 'Why do women get divorced, cheat, and use violence ever more often?' (23 November 2009) - vividly illustrate these notions linked to the view that 'the equality fuss is going too far' (21 August 2009). These claims quite clearly rely on a normative sense of an order wherein women's submissive position is deemed to have been neglected via inappropriate gender performances.

Further exploration of the intersections between our two datasets revealed that the expectations connected with doing gender in the right way are closely linked with those of 
doing race in the right way. One of the clearest examples of this emerged in how some commenters expressed disappointment with Finnish women's purported failure to appreciate white Finnish men and the protection those men offer against non-white migrant men:

The Finnish alpha woman really doesn't accept protection from anyone, especially not from nice and decent Finnish men. (28 August 2017)

In terms of hegemonic masculinity (eg Connell, 2016), this refusal to be protected by Finnish men could be interpreted as violating the norm of submission and of being a passive object of white men's protection against the violence stemming from inferior masculinities. This refusal to be protected is recurrently evaluated in the discussions in line with the logic of masculine white nationalism (Keskinen, 2013), which conflates race and gender with the ideal of the Western white nation. In this logic, Finnish women's alleged tendency to not value white Finnish men's position as their protector and a national guardian is constructed as threatening the nation and its values. This is evident in, for instance, claims about 'excessively tolerant whores', who are accused of 'jeopardising our moral order by letting migrants come here and by defending their misdeeds' (23 August 2017). In an echo of what previous research examining Finnish and Swedish online discussion has shown, anti-racist women are often cast in our data as 'race traitors' who, for exhibiting disloyalty to their society and their 'own people', are shamed as 'tolerance whores' (Sundén \& Paasonen, 2018), and thus cast as lacking moral value.

These portrayals of Finnish women demarcate hierarchies not only between white and non-white men and between white men and white women but also among white women. Even though femininity is not symbolically associated with dominance in the same way that particular versions of masculinity are, it can allow access tosymbolic capital when attached to 
other valued dispositions, such as whiteness (Skeggs, 2005). The value given to hegemonic whiteness not only positions those marked 'white' as superior to those marked 'non-white' but also inferiorises characteristics associated with 'being white' that deviate from dominant ideals connected with whiteness and thereby function as tools for devaluation (Hughey, 2010). Our analysis can therefore be seen as delving into the construction of some Finnish women as symbolically representing 'failed white femininities'. Though the discussants refer to women mainly as representatives of the generic category 'women', the devaluation we have traced above is specifically targeted at those Finnish women who are seen as violating gendered and racialised norms. It is noteworthy that even though the posts' authors seldom identify themselves by gender, we can presume that white Finnish women too participate in performing these moral evaluations (recall that our datasets include threads from several discussion fora targeting women in particular). Indeed, the literature (eg Keskinen, 2018) attests that some Finnish women have become active in anti-immigration and right-wing populist groups, often drawing on both traditional definitions of femininity and liberal understandings of gender equality in this. We suggest that this is linked with the potential of moral value that is attached to the position of an object of protection that is made available in the discourse of violent migrant men, and that constitutes the opposite of failed femininities. This potential for value distinguishes the portrayal of Finnish women from that of migrant men construed as irredeemably threatening.

In the posts, those who represent 'failed white femininities' (overly dominant/tolerant women, as well as those deemed violent) are frequently constructed as legitimate objects of devaluation, derision, exclusion, and corrective action of various sorts:

Now, finally we need to get women's violence under control! Now we sacrifice children and men for nothing at the altar of violence by focusing only on 
violence inflicted by men on women! Now we finally need to end all this distortion and lying done on women's behalf against men! (15 December 2015)

The similarities between portrayals of non-white migrant men and Finnish women extend to these calls for remedial action. The extract below shows how the lack of control attached to these groups, along with Finnish women's and migrant men's alleged disrespect for Finnish men and for the nation and its values they seek to protect, serves as justification for Finnish men's efforts to put them and the societal situation in order, violently if need be. Here, then, Finnish women and migrant men have become objects of justified retaliatory violence by Finnish men, who are called upon to actively take charge of the allegedly dire state of society.

Finnish men, you should now fix yourself and your country at last. Get those hags and migrants under control; it shouldn't be too hard a task for you. Who cares about penalties if you get to teach some bastard a lesson? (30 November 2015)

Akin to these calls for action, found in both datasets is occasional violent silencing of those who express dissenting views. There is a recurring statement that 'man-haters' - those Finnish women who are portrayed as unfairly accusing white Finnish men of violence against women or as excusing violence committed by Finnish women or by non-white migrant men should 'just shut the fuck up' (29 November 2015). Sometimes the hate circulating in these discussions culminates in a sense that it is fitting to threaten the dissenters, mostly assumed or constructed aswomen, with violence - for reason of their nonconformity with the views reiterated in the discussions: 
Migrants arriving from the Middle East and Africa commit rape 17 times more often than native Finns do. Think about when hundreds of thousands of those worthless people arrive and there will be rapes every day. So don't you come here, filthy animal, to squawk about things you don't know anything about or understand. I hope this cow will be beaten by somebody. What a whore! (29 November 2015)

In the extract above, the immorality and worthlessness of the dissenter (assumed to be a woman) is constructed by employing derogatory gendered terms ('cow' and 'whore'), in a manner strikingly similar to that in which non-white migrant men are cast here as 'worthless people' - and indeed, elsewhere in the discussions, often depicted as animals or over-sexual. This is linked with the commentator being asserted to possess diminished capacity to make judgements and an associated lack of knowledge. In this, the example vividly illustrates what is often at stake in online discussions about violence: claim-making and struggles for not only moral value but also the authority to evaluate and criticise others and their moral worth (Skeggs, 1997). In these struggles, the association between moral virtue and white masculinity is reaffirmed through processes whereby the latter is linked with non-violence, rationality, selfcontrol, and respectability with the help of images of non-white migrant men and Finnish women built on a lack of these attributes. Paradoxically, however, this is coupled with violent silencing of any criticism of white masculinity, silencing for which these portrayals are taken as justification.

\section{Conclusions}

In this article, we have analysed the dynamics and discursive processes at play in struggles over value within the context of online discussions about violence committed by women, on one 
hand, and migrant men, on the other. By illustrating how moral evaluations are enacted in the two sets of discussions and considering them side by side, the analysis shed light on the intertwined reproduction of gendered and racialised hierarchies in contemporary context, characterised as it is by structural changes that have influenced both gender relations and the ethnic composition of many of the nations of Europe, Finland among them. We suggest that the parallel crises of white hegemony and male hegemony are recurrently projected on the images created of women and migrant men, whom the discussions thereby often construct as hateful and morally despicable. Furthermore, this examination revealed historical continuity exhibited in both sets of conversations - as the identified meanings and the modes of making evaluations stretch back to moral distinctions that have long facilitated the maintenance of white masculinity's powerful position in relation to femininities and to othered masculinities alike -coupled with flexible tailoring to the contemporary, local context for meaning-making.

This customisation reflects the particularities of the local context in that it relies heavily on assumptions related to gender equality as a central Finnish value and also the idea that this has already been largely achieved, to the point of having gone 'too far'. By analysing the two datasets side by side, we have been able to lay bare these contradictory and intersecting references to gender equality and their parallel functions in the reproduction of gendered and racialised hierarchies. While highlighting equality as a Finnish value does the work of excluding migrant men from national belonging, the notion of equality having gone too far functions similarly in legitimising the exclusion of certain groups of women from the circuits of moral value. It is noteworthy that, although the women constructed as deserving such exclusion seem racially unmarked, their construction as such is informed by whiteness and the gendered meanings associated with it in the Nordic context (Horsti, 2017): the privilege linked to whiteness is inextricable from the claims about women's power exceeding men's, while at the same time the figure of an excessively violent, dominant, tolerant, and/or vocal woman encapsulates 
doing whiteness and femininity in the wrong way. This gendered and racialised impropriety serves as justification for directing hate and violent action at such women in ways that bear an intriguing resemblance to the utilisation of the posts' constructions of non-white migrant men as objects of hate. Furthermore, this female figure stands in stark contrast to how nonwhite migrant women are commonly portrayed in the Finnish context as oppressed products of patriarchal cultures (Keskinen, 2018).

In addition to justifying hate and violence, the portrayals constructed in these discussions are particularly harmful for their capacity as tools for silencing efforts to speak out and otherwise act against gendered violence that Finnish white men direct at women and to resist racism and violent exclusion of migrants. Therefore, an ongoing need exists for critical analyses that provide tools for deconstructing, questioning, and de-legitimating the dynamics of discourse and affective patterns that coalesce both online and offline around the topic of gendered violence, as well as gendered and racialised social relations in general. With the links revealed between the dynamics in the two, differently focused sets of discussions about violence, this paper is one such contribution.

\section{Funding}

This research has been conducted as a part of the project "Social inequalities and discourses of violence" funded by the Kone Foundation, Finland.

\section{References}

Baird, B. (2009). Morality and patriarchal white sovereignty. International Feminist Journal of Politics, 11(3), 372-391. 
Bou-Franch, P., \& Garcés-Conejos Blitvich, P. (2014). Gender ideology and social identity processes in online language aggression against women. Journal of Language Aggression and Conflict, 2(2), 226-248.

Bourdieu, P. (1989). Social space and symbolic power. Sociological Theory, 7, 14-25.

Brubaker, R. (2017). Between nationalism and civilizationism: The European populist moment in comparative perspective. Ethnic and Racial Studies, 40(8), 1191-1226.

Campbell, A., \& Muncer, S. (1994). Men and the meaning of violence. In J. Archer (Ed.), Male Violence (pp. 332-351). London, UK: Routledge.

Clarke, K. (2011). The paradoxical approach to intimate partner violence in Finland. International Perspectives in Victimology, 6(1), 9-19.

Connell, R. (2016). Masculinities in global perspective: Hegemony, contestation, and changing structures of power. Theory and Society, 45(4), 303-318.

Dragiewicz, M. (2011). Equality with a vengeance: Men's rights groups, battered women, and antifeminist backlash. Boston, MA: Northeastern University Press.

Dragiewicz, M., \& Burgess, J. (2016). Domestic violence on \#qanda: The 'Man' question in live Twitter discussion on the Australian Broadcasting Corporation's Q\&A. Canadian Journal of Women and the Law, 28(1), 211-229. 
European Union Agency for Fundamental Rights (2014). Violence against women: An EU-wide survey - main results report. Retrieved from http://fra.europa.eu/en/publication/201 4/violence-against-women-eu-wide-survey-main-results-report.

Farris, S.D. (2017). In the name of women's rights: The rise of femonationalism. Durham and London, UK: Duke University Press.

Ging, D. (2017). Alphas, betas, and incels: Theorizing the masculinities of the manosphere. Men and Masculinities, 1-20 (doi: 1097184X17706401).

Heiskanen, M., \& Ruuskanen, E. (2010). Tuhansien iskujen maa: Miesten kokema väkivalta Suomessa ['The land of thousands of blows: Violence experienced by men in Finland']. Helsinki, Finland: European Institute for Crime Prevention and Control.

Horsti, K. (2017). Digital Islamophobia: The Swedish woman as a figure of pure and dangerous whiteness. New Media \& Society, 19(9), 1440-1457.

Hughey, M. (2010). The (dis)similarities of white racial identities: The conceptual framework of 'hegemonic whiteness'. Ethnic and Racial Studies, 33(8), 1289-1309.

Keskinen, S. (2013). Anti-feminism and white identity politics: Political antagonisms in radical right-wing populist and anti-immigration rhetoric in Finland. Nordic Journal of Migration Research, 3(4), 225-232.

Keskinen, S. (2018). The 'crisis' of white hegemony, neonationalist femininities and antiracist feminism. Women's Studies International Forum, 68, 157-163. 
Kimmel, M. (2013). Angry white men: American masculinity at the end of an era. New York, NY: Nation Books / Perseus.

Magnusson, E., Rönnblom, M., \& Silius, H. (Eds.) (2008). Critical studies of gender equalities: Nordic dislocations, dilemmas and contradiction. Gothenburg, Sweden: Makadam.

Markham, A., \& Buchanan, E. (2012). Ethical decision-making and Internet research: Recommendations from the AoIR Ethics Working Committee (Version 2.0). Association of Internet Researchers. Retrieved from http://www.aoir.org/reports/ethics2.pdf.

Nagel, J. (2003). Race, ethnicity and sexuality: Intimate intersections, forbidden frontiers. Oxford, UK: Oxford University Press.

Pantti, M. (2016). 'Despicable, disgusting, repulsive!!!' Public emotions and moralities in online discussions about violence towards refugees. Javnost - The Public, 23(4), 363-381.

Pöyhtäri, R., Haara, P., \& Raittila, P. (2013). Vihapuhe sananvapautta kaventamassa ['Hate speech limiting freedom of speech']. Tampere, Finland: Tampere University Press.

Saresma, T. (2018). Gender populism: Three cases of Finns Party actors' traditionalist anti-feminism. In U. Kovala, E. Palonen, M. Ruotsalainen, \& T. Saresma (Eds.), Populism on the loose (pp. 177-200). Jyväskylä, Finland: Jyväskylän yliopisto.

Skeggs, B. (1997). Formations of class and gender: Becoming respectable. London, UK: SAGE. 
Skeggs, B. (2005). The making of class and gender through visualizing moral subject formation. Sociology, 39(5), 965-982.

Skeggs, B., \& Loveday, V. (2012). Struggles for value: Value practices, injustice, judgement, affect and the idea of class. The British Journal of Sociology, 63(3), 472-490.

Sundén, J., \& Paasonen, S. (2018). Shameless hags and tolerance whores: Feminist resistance and the affective circuits of online hate. Feminist Media Studies, 18(4), 643-656.

Taylor, S. (2001). Locating and conducting discourse analytic research. In M. Wetherell, S. Taylor, \& S. J. Yates (Eds.), Discourse as data: A guide for analysis (pp. 5-48). London, UK: SAGE.

Törnberg, A., \& Törnberg, P. (2016). Combining CDA and topic modeling: Analyzing discursive connections between Islamophobia and anti-feminism on an online forum. Discourse \& Society, 27(4), 401-422.

Tyler, I. (2015). Classificatory struggles: Class, culture and inequality in neoliberal times. The Sociological Review, 63, 493-511.

Young, I. M. (2003). The logic of masculinist protection: Reflections on the current security state. Signs, 29(1), 1-25.

Yuval-Davis, N. (1997). Gender and nation. London, UK: SAGE. 